\title{
SRPK2 Phosphorylates Tau and Mediates the Cognitive Defects in Alzheimer's Disease
}

\author{
Yi Hong, ${ }^{1}$ Chi Bun Chan, ${ }^{1}$ Il-Sun Kwon, ${ }^{1}$ Xuekun Li, ${ }^{2}$ Mingke Song, ${ }^{3}$ Hyun-Pil Lee, ${ }^{4}$ Xia Liu, ${ }^{1}$ Pradoldej Sompol, ${ }^{1}$ \\ Peng Jin, ${ }^{2}$ Hyoung-gon Lee, ${ }^{4}$ Shan Ping $\mathrm{Yu},{ }^{3}$ and Keqiang $\mathrm{Ye}^{1}$ \\ Departments of ${ }^{1}$ Pathology and Laboratory Medicine, ${ }^{2}$ Human Genetics, and ${ }^{3}$ Anesthesiology, Emory University School of Medicine, Atlanta, Georgia \\ 30322, and ${ }^{4}$ Department of Pathology, Case Western Reserve University School of Medicine, Cleveland, Ohio 44106
}

Serine-arginine protein kinases 2 (SRPK2) is a cell cycle-regulated kinase that phosphorylates serine/arginine domain-containing proteins and mediates pre-mRNA splicing with unclear function in neurons. Here, we show that SRPK2 phosphorylates tau on S214, suppresses tau-dependent microtubule polymerization, and inhibits axonal elongation in neurons. Depletion of SRPK2 in dentate gyrus inhibits tau phosphorylation in APP/PS1 mouse and alleviates the impaired cognitive behaviors. The defective LTP in APP/PS1 mice is also improved after SRPK2 depletion. Moreover, active SRPK2 is increased in the cortex of APP/PS1 mice and the pathological structures of human Alzheimer's disease (AD) brain. Therefore, our study suggests SRPK2 may contribute to the formation of hyperphosphorylated tau and the pathogenesis of AD.

\section{Introduction}

Neuronal morphology is tightly controlled by the dynamic assembly and disassembly of microtubule cytoskeleton network, which is supported and regulated by microtubule-associated proteins (MAPs). Tau is a core MAP that predominantly localizes in axons. It contains three functional domains: an N-terminal projection domain, a C-terminal domain of microtubule-binding repeats and a short tail sequence (Ittner and Götz, 2011). The major functions of tau are stabilization of microtubules and regulation of motor-driven axonal transport (Götz et al., 2006). Binding of tau with microtubule is regulated by its phosphorylation status, which changes its structural morphology and causes its dissociation from microtubule to form the paired helical filament (PHF) (Billingsley and Kincaid, 1997; Dolan and Johnson, 2010). As a result, the microtubule network is disrupted in pathological conditions like Alzheimer's disease (AD), in which tau is abnormally phosphorylated (Martin et al., 2011).

Serine-arginine protein kinases (SRPK) is a family of cell cycle-regulated kinases that phosphorylate serine/arginine (SR) domain-containing proteins in the nuclear speckles to mediate pre-mRNA splicing (Giannakouros et al., 2011). They also regu-

\footnotetext{
Received July 11, 2012; revised Sept. 21, 2012; accepted Sept. 28, 2012

Author contributions: Y.H. and K.Y. designed research; Y.H., C.B.C., I.-S.K., X.L., H.-P.L., X.L., and P.S. performed research; Y.H., C.B.C., X.L., M.S., H.-P.L., P.J., H.-g.L., S.P.Y., and K.Y. analyzed data; Y.H., C.B.C., and K.Y. wrote the paper.

The work was supported by a grant from NCI, NIH (NS060680) to K.Y. and from NIA, NIH (AG028679) to H.-g. L. We thank the Viral Core Facility of Emory University and Dr. Xinping Huang who provided the lentiviral vectors and HEK293FT cells, and the Rodent Behavioral Core of Emory University School of Medicine for performing the water maze test. We also thank Dr. Xiang-Dong Fu (UCSD) for his critical reading and comments on this manuscript.

The authors declare no competing financial interests.

Correspondence should be addressed to either Dr. Chi Bun Chan or Dr. Keqiang Ye, Department of Pathology and Laboratory Medicine, Emory University School of Medicine, 615 Michael Street, Atlanta, Georgia 30322. E-mail: cbchan@emory.edu or kye@emory.edu.

DOI:10.1523/JNEUROSCI.3300-12.2012

Copyright $\odot 2012$ the authors $\quad 0270-6474 / 12 / 3217262-11 \$ 15.00 / 0$
}

late the subcellular localization of splicing factors SF2/ASF through phosphorylating these proteins (Koizumi et al., 1999). In addition to the major function as a SR protein kinase, SRPK2 is involved in the cell cycle regulation, cell proliferation, and apoptosis (Jang et al., 2009; Giannakouros et al., 2011). The two SRPK paralogs (SRPK1 and SRPK2) have different tissue specificity in that SRPK1 is predominantly expressed in pancreas, whereas SRPK2 is enriched in the brain, although both are also coexpressed in other peripheral tissues (Wang et al., 1999). The brain-enriched expression of SRPK2 implies that it may play an important role in controlling neuronal functions. In agreement with this notion, we have previously shown that Akt phosphorylates SRPK2 on T492 and elicits its binding to 14-3-3, which mediates cell cycle progression and cell death in neurons (Jang et al., 2009). Moreover, we found that SRPK2 is a caspase substrate, which promotes neuronal apoptosis after caspase cleavage (Hong et al., 2011).

In this study, we demonstrate that that activity of SRPK2 is focally enhanced in both human and rodent brains of AD, implying SRPK2 is correlated with AD progression. Depleting SRPK2 in the hippocampus alleviates the memory defect and improves the induction of long-term potentiation in APP/PS1 mice. SRPK2 also phosphorylates tau on S214 and suppresses microtubule polymerization. Our finding that SRPK2 phosphorylates tau and is activated in AD neurons suggests SRPK2 is implicated in the pathogenesis of $\mathrm{AD}$.

\section{Materials and Methods}

Reagents. Anti-myc and anti-APP antibodies were purchased from Cell Signaling Technology. Anti-Tau-1 antibody was from Millipore. Antiphospho-Tau S214 antibody and A $\beta 1-42$ ELISA kit were from Invitrogen. Anti-SRPK2 antibody was from BD Bioscience. Anti-phospho-SRPK2 T492 antibody was generated by immunizing rabbit with the phospho-peptide, and the resulting serum was affinity purified with the phospho-peptide conjugated onto the affigel. Anti-phosphorylated Tau antibody (AT8) was 
purchased from Pierce. Anti-tubulin antibody, 4,6-diamidino-2phenylindole (DAPI), A $\beta 1-42$, and Thioflavin-S were from SigmaAldrich. $\mathrm{A} \beta 1-42$ fibrils were produced by dissolving the lyophilized peptide in $\mathrm{H}_{2} \mathrm{O}$ and incubating at $37^{\circ} \mathrm{C}$ for $3 \mathrm{~d}$ as reported previously (Lorenzo and Yankner, 1994). Glutathione Sepharose 4B was purchased from GE Healthcare. $\left[\gamma^{32} \mathrm{P}\right]$-ATP was from PerkinElmer. Protein kinase A (PKA), cyclin-dependent kinase 5 (CDK5), and glycogen synthase kinase (GSK) inhibitors were from Calbiochem. Bovine Tubulin protein was purchased from Cytoskeleton. SRPK inhibitor (SRPIN340) was from Maybridge.

Plasmids. The coding sequence of human SRPK2 was inserted into pFUGW between XbaI and MFE I or into pEGX-4T-2 between SalI and NotI. Tau fragments were inserted into pEGX-4T-2 vector between SalI and NotI. The shRNA sequences targeting SRPK2 were fused into the lentiviral vector pFH1UGW. The sites indicated for tau protein represent the amino acids in the longest form of human tau protein (Tau441). The target sequences recognized by shSRPK2 (5'GCAGAGAGTGATTACACGTAT-3') were acquired from SigmaAldrich MISSION shRNA library.

Cell culture and transient transfection. HEK293 and HEK293FT cells were maintained in DMEM supplemented with $10 \%$ fetal bovine serum, $2 \mathrm{mg} / \mathrm{ml}$ glutamine, and $100 \mathrm{U}$ penicillin-streptomycin at $37^{\circ} \mathrm{C}$ in a humidified incubator containing $5 \% \mathrm{CO}_{2}$. Primary rat cortical and hippocampal neurons were cultured as previously described (Jang et al., 2009). Transfection of HEK293FT cells for lentivirus packaging was performed using calcium phosphate precipitation method. Transfection of primary neuron was carried out using Lipofectamine 2000 (Invitrogen) according to the manufacturer's instructions. Twenty-four hours after transfection, cells were fixed with $4 \%$ PFA, immunostained with antiTau- 1 antibody, and analyzed using fluorescent microscopy. On average, 20 cells per transfection were counted. The length of the primary neurite was measured using ImageJ software from NIH.

In vitro kinase assay. GST-tagged SRPK2 proteins and Tau proteins were expressed in E. coli and purified with the Glutathione Sepharose 4B Beads. Purified SRPK2 proteins $(1 \mu \mathrm{g} / \mathrm{each})$ were incubated with tau proteins $(1 \mu \mathrm{g} / \mathrm{each})$ in kinase reaction buffer ( $25 \mathrm{~mm}$ Tris, $\mathrm{pH} 7.5$, with $10 \mathrm{~mm} \mathrm{MgCl}$, 2 mм DTT, $5 \mathrm{~mm} \beta$-glycerolphosphate, $0.1 \mathrm{~mm} \mathrm{Na}_{3} \mathrm{VO}_{4}$, and $2 \mathrm{~mm}$ EGTA) containing $20 \mu \mathrm{M}$ ATP and $1 \mu \mathrm{Ci}$ of $\left[\gamma^{-32} \mathrm{P}\right]$-ATP for $30 \mathrm{~min}$ at $30^{\circ} \mathrm{C}$. Reactions were then separated in SDS-PAGE and analyzed by autoradiography.

Immunoprecipitation and Western blot analysis. Cells were washed with ice-cold PBS and lysed in coimmunoprecipitation (CoIP) buffer $(50 \mathrm{~mm}$ Tris- $\mathrm{HCl}$ [pH 7.5], 150 mм NaCl, 1\% Nonidet P-40, 5 mм EDTA, 5 mм EGTA, $15 \mathrm{~mm} \mathrm{MgCl}_{2}$, $60 \mathrm{~mm} \beta$-glycerophosphate, $0.1 \mathrm{~mm}$ sodium orthovanadate, $0.1 \mathrm{~mm} \mathrm{NaF}, 0.1 \mathrm{~mm}$ benzamide, $10 \mu \mathrm{g} / \mathrm{ml}$ aprotinin, 10 $\mu \mathrm{g} / \mathrm{ml}$ leupeptin and $1 \mathrm{~mm}$ PMSF) at $4^{\circ} \mathrm{C}$ for $2 \mathrm{~h}$ with rotation. Detergent insoluble materials were removed by centrifugation, and CoIP was performed as before (Chi et al., 2009). Immunoprecipitated proteins were separated by SDS-PAGE and then transferred to a nitrocellulose membrane. The membrane was blocked with TBS containing $5 \%$ nonfat milk and $0.1 \%$ Tween 20 (TBST) at room temperature (RT) for $1 \mathrm{~h}$, followed by the incubation with primary antibody at $4^{\circ} \mathrm{C}$ overnight, and with the secondary antibody at RT for $1 \mathrm{~h}$. After washing with TBST, the membrane was developed using the enhanced chemiluminescent (ECL) detection system.

Microtubule polymerization assay. Recombinant Tau was incubated with GST, GST-SRPK2, or GST-SRPK2-KD for in vitro phosphorylation at $37^{\circ} \mathrm{C}$ for $1 \mathrm{~h}$, before the incubation with tubulin. The in vitro microtubule polymerization assay was performed using $1.5 \mu \mathrm{M}$ tau and $20 \mu \mathrm{M}$ tubulin as reported previously (Yoshida and Goedert, 2006).

Analysis of Tau aggregation. Tau aggregation was detected as previously described (Zhang et al., 2006). Briefly, rat neurons were isolated from E17 fetus and cultured for $10 \mathrm{~d}$. The cells were then infected with various lentiviruses for $48 \mathrm{~h}$, followed by homogenization in breaking buffer ( 0.25 м sucrose; 10 mM HEPES, pH 7.2; 1 mM MgOAc $_{2}$; protease inhibitor mixture). Cytosol was prepared from postnuclear supernatant by ultracentrifugation for $1 \mathrm{~h}$ at 190,000 $\times g$. The resulting membrane pellet was resuspended and incubated on ice for 30 min with $5 \mu \mathrm{M}$ nocodazole, followed by ultracentrifugation for $1 \mathrm{~h}$ at $190,000 \times g$ to pro- duce postnocodazole supernatants containing the microtubuleassociated tau. The generated pellets containing both membraneassociated and aggregated tau were further extracted using $100 \mathrm{~mm}$ sodium carbonate buffer $(\mathrm{pH} 11.5)$ at $4^{\circ} \mathrm{C}$ for $30 \mathrm{~min}$. The post- $\mathrm{Na}_{2} \mathrm{CO}_{3}$ pellets were prepared by ultracentrifugation at $190,000 \times g$ for $1 \mathrm{~h}$ and washed with $1 \%$ SDS to produce a fraction containing tau aggregates. All the fractions were quantified for equal amount of protein, separated with SDS-PAGE, and detected with anti-Tau-1 antibody and anti-pS214 Tau antibody.

Lentivirus packaging. Lentivirus packaging system (pFUGW or pFH1UGW, pCMVAR8.92, and pVSVG) was acquired from the Viral Core Facility of Emory University. Transfection of the lentiviral vectors were performed in HEK293FT cells (50-60\% confluent) with calcium phosphate reagents. After $16 \mathrm{~h}$, the transfection media were discarded, and the cells were washed with sterile PBS and incubated with prewarmed fresh culture media. After $48 \mathrm{~h}$ incubation, the cell culture media were collected, and the lentiviral particles were concentrated by ultracentrifugation at 22,000 RPM (SW28) for $2 \mathrm{~h}$ at $4^{\circ} \mathrm{C}$. All the lentivirus-containing materials were handled according to the Biosafety regulation of Emory University.

Stereotaxic injection of lentivirus in mouse dentate gyrus. In vivo lentiviral grating was performed as described previously (Szulwach et al., 2010) with a few modifications. In brief, 12-month-old WT and APP/PS1 male mice were anesthetized with hydrochloride, and lentivirus (LV, $2.5 \mu$ l with titer $>1 \times$ $10^{8} / \mathrm{ml}$ ) was injected stereotaxically into the dentate gyrus (DG) using the following coordinates relative to bregma: anteroposterior, $-(1 / 2) \times$ difference (d) between bregma and lambda in anteroposterior coordinates, $\mathrm{mm}$; lateral, $\pm 1.8 \mathrm{~mm}$ (if d $>1.6$ ), or otherwise $\pm 1.7 \mathrm{~mm}$; and ventral, $-1.9 \mathrm{~mm}$ (from dura).

Human brain tissue. Using a protocol approved by the Case Western Reserve University IRB, human brain tissue was obtained postmortem and fixed in either routine formalin or methacarn (methanol:choloform: acetic acid; 6:3:1 v/v/v), dehydrated through ascending ethanol, embedded in paraffin, cut into $5 \mu \mathrm{m}$ sections, and mounted on saline-coated slides. The ages of control cases were similar to the cases with the $\mathrm{AD}$ cases used in this study.

Immunohistochemistry. Immunohistochemistry was performed by using the peroxidase antiperoxidase protocol. Briefly, tissue sections were deparaffinized in xylene, hydrated through descending ethanol, and endogenous peroxidase activity was eliminated by incubation in 3\% hydrogen peroxide in methanol for $5 \mathrm{~min}$. After antigen-retrieval in boiling sodium citrate buffer $(10 \mathrm{~mm})$, the sections were incubated with primary antibodies [anti-pphospho-SRPK2 T492; 1:500, anti-phospho-Tau S214; 1:100 and anti-PHF Tau (AT8) 1:500] for overnight at $4^{\circ} \mathrm{C}$. The signal was developed using Histostain-SP kit (Invitrogen).

For the double immunofluorescence staining, the sections were incubated overnight at $4^{\circ} \mathrm{C}$ with a mixture of rabbit anti-phospho-SRPK2 T472 and mouse anti-PHF-Tau AT8. After being washed with TBS, the sections were incubated with a mixture of Alexa Fluor 488- and 568coupled secondary antibodies (Invitrogen) for detection. Images were acquired through an AxioCam camera on an Axiovert 200M microscope (Zeiss). Images were then analyzed with the Axiovision software (Zeiss).

Morris water maze. Morris water maze was carried out as previously described (Lee et al., 2010). Acquisition training consisted of 5 test days with four daily trials. Mice entered the maze facing the wall and began each trial at a different entry point in a semi-random order. Trials lasted $60 \mathrm{~s}$ or until the animal mounted the platform with a 15 min intertrial interval. A probe trial was conducted on day 6 wherein the platform was removed, and the animal swam for $60 \mathrm{~s}$, and the time spent in the target quadrant (NW) versus the adjacent and opposite quadrants was recorded. A video camera mounted above the swim arena and linked to TopScan software recorded swim distance, swim speed, and time to platform and was used for tracking and analysis.

Electrophysiological analysis. The mice were anesthetized with isoflurane, decapitated, and their brains were removed into ice-cold artificial CSF (ACSF) containing the following: $124 \mathrm{~mm} \mathrm{NaCl}, 3 \mathrm{~mm} \mathrm{KCl}, 1.25 \mathrm{~mm}$ $\mathrm{NaH}_{2} \mathrm{PO}_{4}, 6.0 \mathrm{~mm} \mathrm{MgCl}, 26 \mathrm{~mm} \mathrm{NaHCO} 3,2.0 \mathrm{~mm} \mathrm{CaCl}_{2}$, and $10 \mathrm{~mm}$ glucose. ACSF was saturated with $95 \% \mathrm{O}_{2}$ and $5 \% \mathrm{CO}_{2}$, at $\mathrm{pH}$ 7.4. Hippocampus was dissected out on an ice-cold base plate and cut into 400$\mu \mathrm{m}$-thick transverse slices with a vibratome (Vibratome 1000 Plus 
A
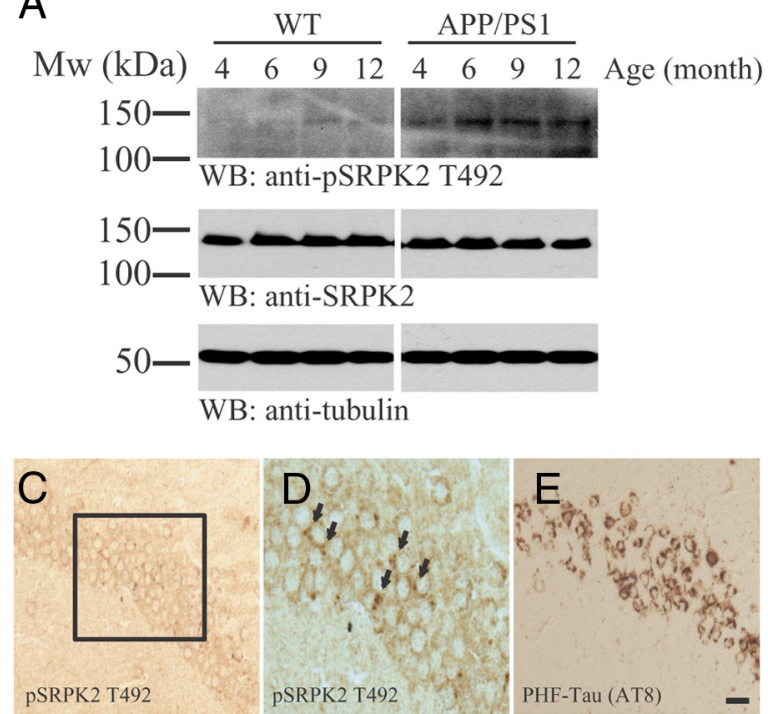

$\mathrm{F}$

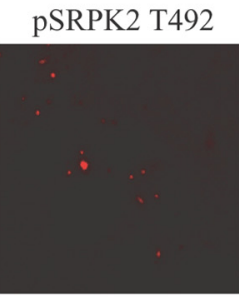

PHF-Tau (AT8)

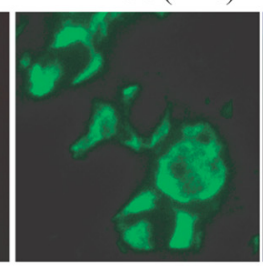

Merge

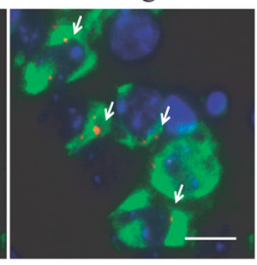

SRPK2/PHF-Tau/DAPI
B

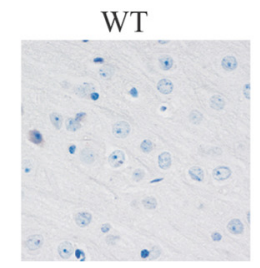

IHC: anti-pSRPK2 T492

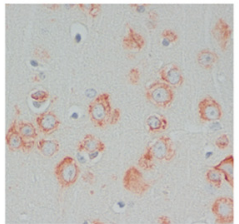

IHC: anti-SRPK2

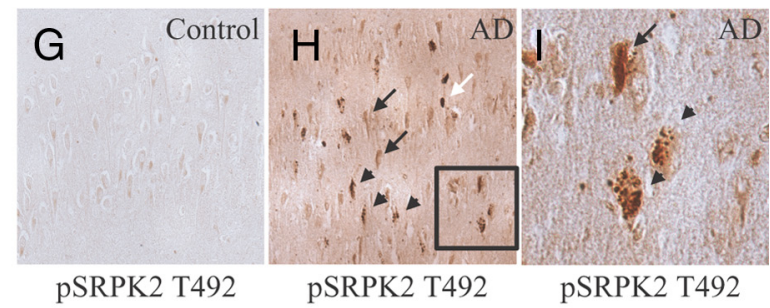

$\mathrm{J}$

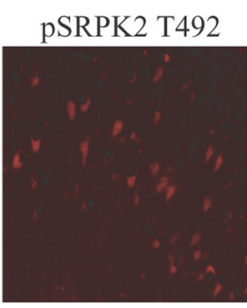

APP/PS1
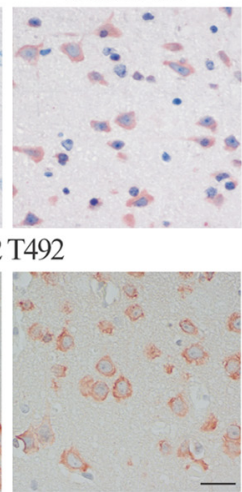

pSRPK2 T492

pSRPK2 T492
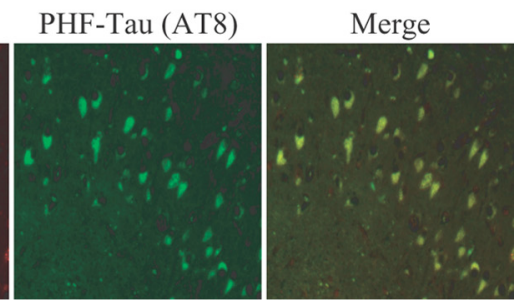

Figure 1. SRPK2 is activated in AD brains. A, Increased SRPK2 T492 phosphorylation in APP/PS1 mice. Western blot analysis using specific antibodies as indicated was performed in cell lysates collected from the cortex of 4- to 12-month-old wild-type and APP/PS1 mice. B, Increased SPRK2 T492 (top) phosphorylations on APP/PS1 (9 months old) cortex. Immunohistochemical staining was performed in paraffin-embedded brain sections $(8 \mu \mathrm{m})$ using various antibodies as indicated. The expression of SRPK2 (bottom) was also shown. Scale bar, 20 $\mu \mathrm{m}$. $\boldsymbol{C}-\boldsymbol{E}$, In 3xTg-AD mice, phospho-SPRK2 T492 signals are found in CA1 neurons (D), where they parallel with the PHF-Tau (AT-8) (E). A higher magnification of the indicated area in $\boldsymbol{C}$ is shown in $\boldsymbol{D}$. Scale bar, $50 \mu \mathrm{m}$. $\boldsymbol{F}$, Phospho-SRPK2 T492 immunoreactivities were colocalized with those of PHF-tau (indicated by white arrows) in 3xTg-AD hippocampus. Scale bar, $10 \mu \mathrm{m} . \mathbf{G}-\boldsymbol{I}$, The immunoreactivity of phospho-SRPK2 T492 is upregulated in the cytoplasm of pyramidal neurons in the hippocampus of AD-affected individuals ( $\boldsymbol{H}$ ) when compared with control brain (G). Phospho-SRPK2 T492 is observed in NFT-bearing neurons (black arrow), GVD-bearing neurons (arrowhead), and Hirano body (white arrow). A higher magnification of the inset of $\boldsymbol{H}$ is shown in $\boldsymbol{I}$. J, Phospho-SRPK2 T492 co-localizes with PHF-tau (AT8) in neurons of human AD brains.

Sectioning System). Slices were collected with a soft brush, and incubated at room temperature $\left(23-24^{\circ} \mathrm{C}\right)$ in ACSF for $60-90$ min before recording. For electrophysiological recording, hippocampal slices were transferred to a small recording chamber (RC-22C, Warner Instruments) on a fixed-stage microscope (Olympus CX-31) and superfused with normal $\mathrm{ACSF}$ at the rate of $3 \mathrm{ml}$ per minute with ACSF at $23-24^{\circ} \mathrm{C}$. For the recording of field excitatory postsynaptic potentials (fEPSPs), a glass microelectrode filled with ACSF with resistance of 3-4 M $\Omega$ was placed in CA3 region, and a $0.1 \mathrm{M} \Omega$ tungsten monopolar electrode was used to stimulate the dentate gyrus of hippocampus. The stimulation output (Master-8; AMPI) was controlled by the trigger function of EPC9 amplifier (HEKA Elektronik). fEPSPs were recorded in current-clamp mode of EPC9. Data were filtered at $3 \mathrm{KHz}$ and digitized at sampling rates of $20 \mathrm{kHz}$ using Pulse software (HEKA Elektronik). In all experiments the stimulus intensity ( $0.2 \mathrm{~ms}$ duration, $30-60 \mu \mathrm{A}$ ) was set to evoke $40 \%$ of the maximum fEPSP initial slope, and the test pulse was applied at a rate of $0.033 \mathrm{~Hz}$. Paired-pulse facilitation (PPF) was examined by applying pairs of pulses that were separated by $10-500 \mathrm{~ms}$ different intervals. To induce tetanus long-term potentiation (LTP) at the mossy fiber-CA3 synapse, one stimulus train of 100 pulses at $100 \mathrm{~Hz}$ was applied. The magnitude of LTP was expressed as the mean percentage of baseline fEPSP initial slope.

Statistical analysis. Data were expressed as mean \pm SEM. All statistical calculations were carried out with the software Prism (GaphPad) by
ANOVA. $p<0.05$ was considered statistically significant. Results were calculated from at least three independent experiments.

\section{Results}

\section{SRPK2 is activated in AD neurons}

In search for new SRPK2 functions in the nervous system, we found that the activity of SRPK2 (as revealed by T492 phosphorylation) (Jang et al., 2009) was significantly increased in the brain of APP/PS1 transgenic mouse, an established animal model of AD that overexpresses mutant forms of amyloid precursor protein (APP) and presenilin (PS) (Trinchese et al., 2004), than the age-matched wild-type control (Fig. $1 A$ ). This elevated SRPK2 activity could be detected in APP/PS1 cortical neurons as early as 4 months of age (Fig. $1 B$ ). Similar observation was made in another transgenic mouse model that expresses $\mathrm{APP}_{\mathrm{Tg} 2576}, \mathrm{PS}_{\mathrm{M} 146 \mathrm{~V}}$, and $\mathrm{Tau}_{\mathrm{P} 301 \mathrm{~L}}(3 \mathrm{xTg}-\mathrm{AD})$ (Oddo et al., 2003). As shown in Figure 1, $C$ and D, phospho-SRPK2 T492 positive cells were found in CA1 neurons, where they paralleled with the tau in the paired-helical filament (PHF-tau) as detected by the AT8 antibody (Spillantini et al., 1996) (Fig. 1E). In double 
A

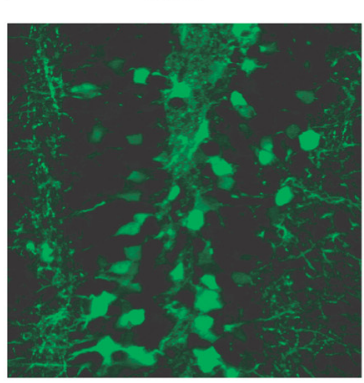

DAPI

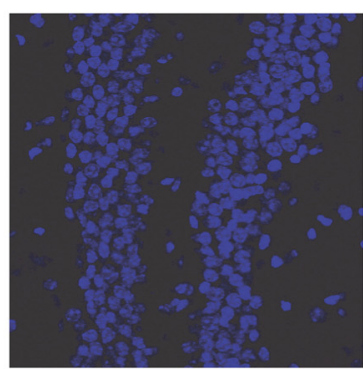

Merge

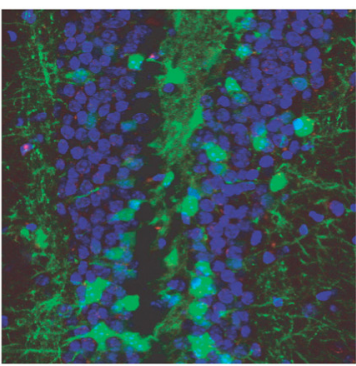

B

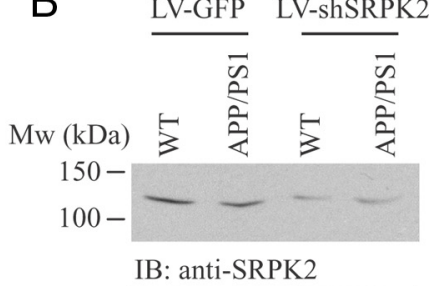

50

IB: anti-tubulin
C

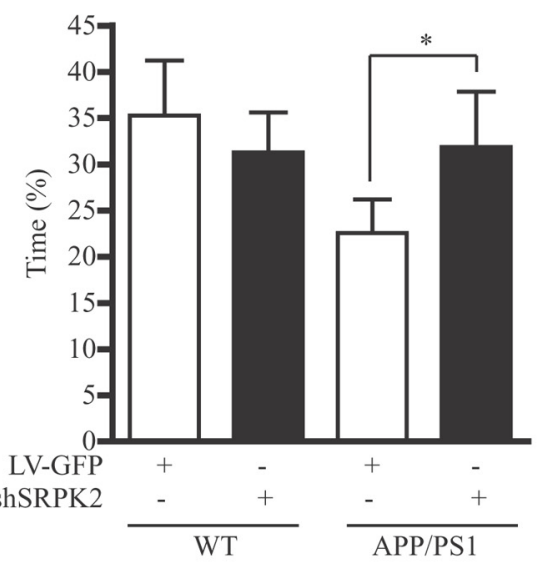

D

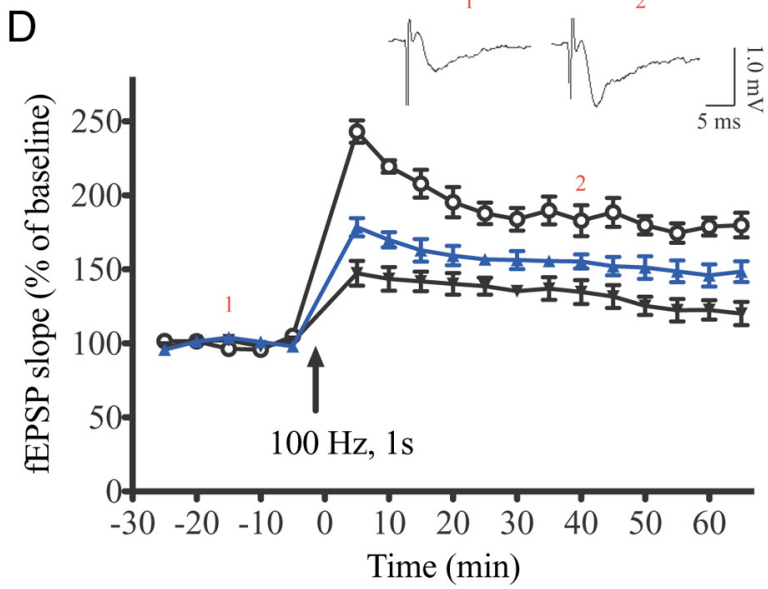

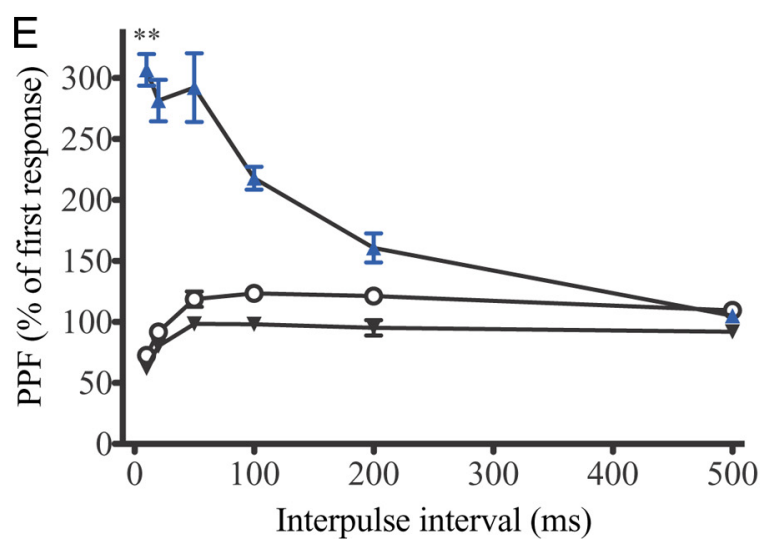

Figure 2. Knockdown SRPK2 expression improves synaptic plasticity in APP/PS1 mouse. A, APP/PS1 mice were injected with LV-shSRPK2 into the DG region. After 2 weeks, the mice were euthanized and the brains were perfused and fixed in $4 \%$ paraformaldehyde. The brains were then sectioned ( $40 \mu \mathrm{m}$ ) and expression of GFP (an indication of infection) was examined under fluorescent microscopy. $\boldsymbol{B}$, Western analysis of SRPK2 expression in lentivirus injected hippocampus. Two weeks after LV-GFP or LV-shSRPK2 injection, the hippocampus of the mice were collected and used for immunoblotting. $C$, Percentage of time that the animals spent in the platform quadrant of the water tank during the probe trial of the Morris water maze test ${ }^{*} p<0.05$, Student's $t$ test, $n=5)$. D. Synaptic plasticity in hippocampus was studied by inducing long-term potentiation at the mossy fiber-CA3 synapse of WT or APP/PS1 brains infected with LV-GFP or LV-shSRPK2 (O: WT-LV-GFP, $\mathbf{\nabla}:$ APP/PS1-LV-GFP, $\mathbf{\Delta}$ : APP/PS1-LV-shSRPK2, $n=6,{ }^{*} p<0.05$, two-way ANOVA). Examples of single trance recordings from WT mice before (1) and after LTP induction (2) were also shown. E, PPF was examined in WT or APP/PS1 brains infected with LV-GFP or LV-shSRPK2 in the dentate gyrus at an interpulse interval from 10 to 500 ms (O:WT-LV-GFP, $\mathbf{\nabla}$ : APP/PS1-LV-GFP, $\mathbf{\Delta}$ : APP/PS1-LV-shSRPK2, $n=6,{ }^{* *} p<0.01$, two-way ANOVA).

immunofluorescence staining, phospho-SRPK2 T492 was found in $19.1 \pm 6.7 \%$ of AT8-positive neuronal cells in 3xTg-AD brain $(n=3)$ (Fig. $1 F)$. SRPK2 T492 phosphorylation was also increased in human $\mathrm{AD}$ brains, which was colocalized with neurofibrillary tangles (NFT), granulovacuolar degeneration (GVD), and Hirano body (Fig. $1 G-I$ ). Moreover, the phospho-SRPK2 T492 signals colocalized with the PHF-tau in the human AD brains (Fig. $1 J$ ). Thus, our results imply that neuronal SRPK2 is activated during the pathological process of $\mathrm{AD}$ in both human and mouse brains.

\section{Depletion of SRPK2 improves the synaptic plasticity in} APP/PS1 mice

If SRPK2 is implicated in the pathological progression of $\mathrm{AD}$, suppressing its expression should alleviate the clinical syndromes. We therefore investigated whether SRPK2 silencing reduced learning and memory impairments in $\mathrm{AD}$ mice since memory deterioration is one of the behavioral hallmarks of $\mathrm{AD}$ (Sperling et al., 2010). Control lentivirus (LV-GFP) or virus overexpressing shSRPK2 (LV-shSRPK2) was bilaterally injected into the DG of WT or APP/PS1 mice at the age of 14 months when the 
$\beta$-amyloid (A $\beta$ ) plaque was stably formed (data not shown). This lentivirus can effectively infect the DG neurons (Fig. 2A) and suppress SRPK2 expression (Fig. 2B). Morris water maze test was then carried out to test the memory of the virus-infected WT or APP/PS1 mice. As illustrated in Figure 2C, APP/PS1 mice spent lesser time in the platform quadrant $(35.3 \pm 6.0 \%$ vs $22.6 \pm$ $3.6 \%)$, which was significantly reversed in the LV-shSRPK2injected mice $(22.6 \pm 3.6 \%$ vs $31.9 \pm 3.1 \%)$. The performance of WT mice injected with LV-shSRPK2 was not significantly altered when compared with the LV-GFP-injected WT mice $(35.3 \pm$ $6.0 \%$ vs $31.3 \pm 4.3 \%)$. The result implies that ablating SRPK2 expression may improve the learning and memory in APP/PS1 but not WT mice. To further delineate how SRPK2 depletion leads to memory amelioration, we investigated electrophysiological changes of single neurons by inducing LTP at the mossy fiber-CA3 synapse of APP/PS1 mice infected with various lentiviruses. As shown in Figure $2 D$, the LTP magnitude was markedly suppressed in LV-GFP-injected APP/PS1 mice when compared with the LV-GFP-injected WT mice. In contrast, the LTP magnitude in APP/PS1 mice was significantly elevated after LVshSRPK2 infection (133.9 $\pm 8.84 \%$ vs $156.9 \pm 9.11 \%$ of baseline, $p<0.05, n=6$ ), suggesting a definite enhancement in synaptic plasticity after SRPK2 depletion. PPF, an indication of presynaptic function, was also examined at an interpulse interval from 10 to $500 \mathrm{~ms}$ (Fig. 2E). The averaged PPF amplitude in LV-GFPinjected APP/PS1 mice $(87.7 \pm 14.25 \%, n=6)$ was lower than the LV-GFP-injected WT mice $(106.2 \pm 20.1 \%, n=6)$, but was significantly increased after LV-shSRPK2 infection (227.4 \pm $81.1 \%, n=6, p<0.01)$. These results suggest a rescued and improved presynaptic function after SRPK2 knockdown in the DG region of hippocampus.

\section{SRPK2 interacts with tau}

Accumulation of phosphorylated tau aggregates in the dendrite of neurons damages synaptic plasticity in AD mouse models (Yoshiyama et al., 2007; Hoover et al., 2010). Given that SRPK2 depletion ameliorated the memory defect of APP/PS1 mice, we thus hypothesized that SRPK2 might modulate the function of tau. Therefore, we tested if SRPK2 associated with tau. As shown in Figure 3A, endogenous SRPK2 bound tau in SH-SY5Y neuroblastoma cells. A similar observation was made in brain lysates from normal and APP/PS1 mice, which showed that both SRPK1 and SRPK2 interacted with tau (Fig. 3B). GST pull-down assay provided a direct interaction between tau and SRPKs (Fig. 3C). To further characterize the SRPK2/tau interaction, we used a series of tau or SRPK2 truncates to explore the binding regions between the two proteins (Fig. 3D,F). In vitro binding assay showed that SRPK2 bound to the proline-rich region [amino acid (aa) 191-250] of tau (Fig. 3E) through its aa sequence 384-438, a region within the spacer between the two kinase domains (Fig. $3 F)$. Together, these results indicate that SRPK2 is a novel interaction partner of tau in neurons.

\section{Tau is a substrate of SRPK2}

In HEK293 cells, we found that overexpression of wild-type (SRPK2 WT) but not the kinase-dead (SRPK2 KD) SRPK2 reduced the mobility of tau in SDS-PAGE, suggesting that tau phosphorylation might be increased in the presence of active SRPK2 (Fig. 4A). To verify whether SRPK2 could phosphorylate tau directly, we conducted an in vitro kinase assay. SRPK2 WT exhibited strong autophosphorylation and potently phosphorylated tau, which were totally abolished when SRPK2 KD was used (Fig. $4 B$, lanes 1 and 2). Our previous study shows that the phos- phorylation status of SRPK2 on T492 by Akt regulates its kinase activity in which the T492D mutant of SRPK2 displays higher kinase activity, whereas T492A mutation inhibits the activity (Jang et al., 2009). Accordingly, SRPK2 T492D exhibited more robust autophosphorylation (band intensity: 1.0 vs 1.61 ) and stronger phosphorylation on tau (band intensity: 1.0 vs 1.34 ) than SRPK2 WT, while SRPK2 T492A showed an impaired autophosphorylation (band intensity: 1.0 vs 0.48 ) and weaker kinase activity toward tau (band intensity: 1.0 vs 0.86 ) (Fig. $4 B$ ). To identify the aa residues that are phosphorylated by SRPK2, we prepared various tau truncation mutants for in vitro kinase assay (Fig. 4C). We found that aa 191-250 in tau could be phosphorylated by SRPK2 (Fig. 4D). Further structural analysis of this region revealed three serines (S208, S210, and S214) in the SR repeats, which represented the potential phosphorylation site for SRPK protein kinases (Fig. $4 E$ ). We thus prepared point mutants of these serine residues to pinpoint the SRPK2 phosphorylation site. While the tau S214A mutation fully abolished the phosphorylation by SRPK2, mutation of the other serine residues (S208, S210) lacked the effect (Fig. $4 F$ ).

To explore whether SRPK2 could phosphorylate tau in neurons, we overexpressed SRPK2 in primary neuron cultures using lentivirus overexpressing wild-type SRPK2 (LV-myc-SRPK2 $\mathrm{WT}$ ) or kinase-dead SRPK2 (LV-myc-SRPK2 KD). Immunoblotting assay showed that overexpression of SRPK2-WT potently increased, whereas SRPK2-KD reduced, tau S214 phosphorylation in neurons (Fig. 4G). To further study the effect of SRPK2 on tau phosphorylation, we infected primary mouse neurons with control lentivirus (LV-con shRNA) or lentivirusexpressing shRNAs against SRPK2. LV-shSRPK2 effectively knocked down SRPK2 in mouse neurons and downregulated phospho-tau S214 (Fig. $4 H$, first and second panels). In cultured primary neurons, SRPK2 predominantly localized in the cell body and neurites and overexpression of SRPK2 strongly enhanced the phosphorylation of tau on S214 (Fig. 4I). In contrast, knockdown of SRPK2 expression evidently inhibited tau S214 phosphorylation (Fig. $4 J$ ). To compare the relative contribution of SRPK2 with other kinases that also phosphorylate tau on S214, we inhibited PKA, CDK5, and GSK3 with small inhibitors (H89, roscovitine, and SB216763, respectively) in cultured neurons to monitor the tau phosphorylation in response to SRPK2 overexpression. In control virus-infected cells, inhibition of PKA or GSK3 significantly reduced tau S214 phosphorylation (Fig. $4 K$ ). SRPK2 overexpression resulted in robust tau S214 phosphorylation even in the presence of PKA and CDK5 inhibitors. However, tau S214 phosphorylation was not increased after SRPK2 overexpression when GSK3 was inhibited (Fig. $4 K$ ). Together, these results suggest that tau is a substrate of SRPK2 and S214 is the major phosphorylation residue.

\section{SRPK2 mediates tau phosphorylation in vivo}

We next tested whether SRPK2 is critical in mediating tau S214 phosphorylation in APP/PS1 mice. The number of phospho-tau S214 positive neurons in DG was greatly enhanced in APP/PS1 mice (Fig. 5A, bottom left). Depletion of SRPK2 reduced the phospho-Tau S214 level in the APP/PS1 DG region (Fig. 5A, bottom right), whereas the virus did not show any impact on phospho-tau S214 levels in WT mice (Fig. 5A, top). Tau S214 phosphorylation level was also comparable between the LV-GFPinjected WT mice and those mice without any virus injection. Apoptotic cells (as revealed by the presence of active caspase 3 ) could be readily detected in the DG of APP/PS1 mice (1.5 \pm $0.32 \%$ of neurons in DG, $n=3$ ) (Fig. $5 B$, bottom left), which fits 
A

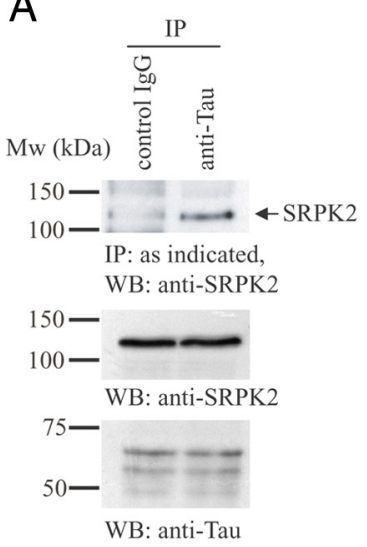

D

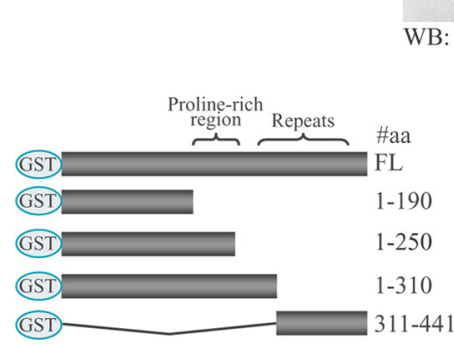

\section{$E$}

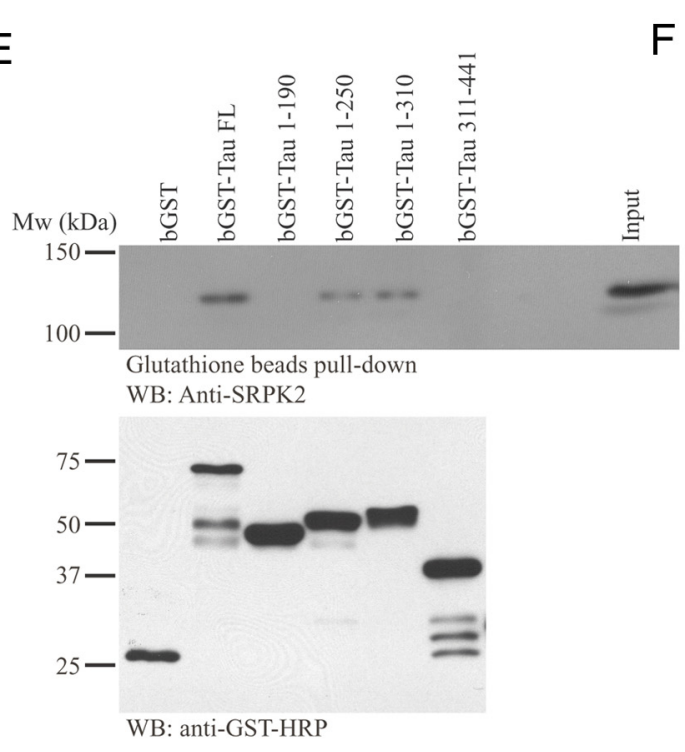

F
B

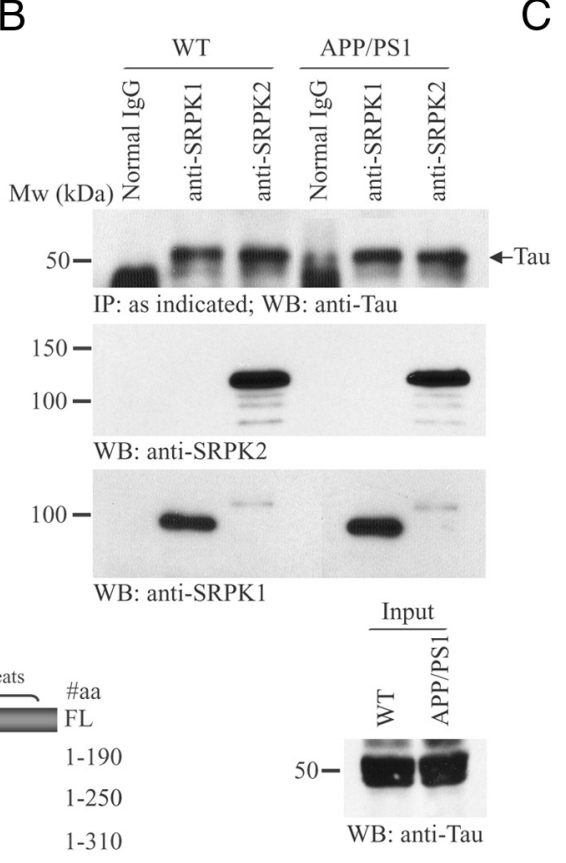

C

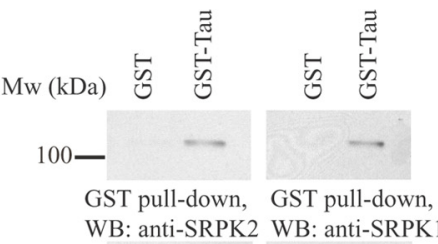

WB: anti-SRPK2 WB: anti-SRPK

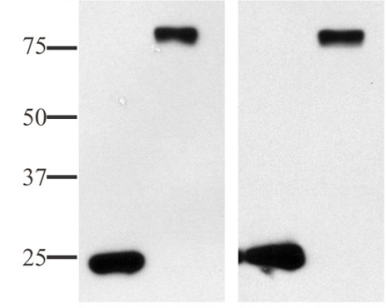

WB: anti-GST-HRP Input

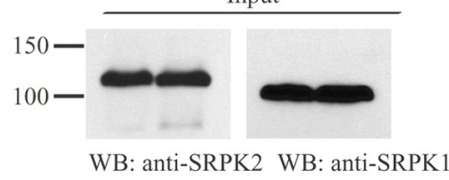

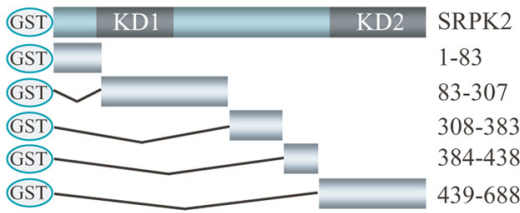

G

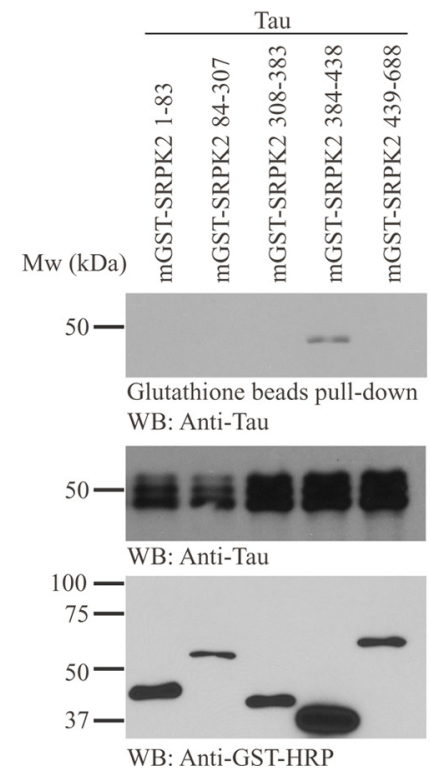

Figure 3. Tau binds SRPK2 in vitro and in vivo. A, SRPK2 interacts with tau in SH-SY5Y neuroblastoma cells. Cell lysates from SH-SY5Y were incubated with control lgG or anti-Tau-1 antibody, followed by immunoprecipitation. The precipitated proteins were resolved by SDS-PAGE and detected with anti-SRPK2 antibody (top). Inputs of SRPK2 (middle) and tau (bottom) were also examined. B, SRPK2 and SRPK1 interact with tau in mouse brain. Brain lysates collected from WT or APP/PS1 mouse brain were subjected to immunoprecipitation using anti-SRPK1 or anti-SRPK2 antibody. The precipitated proteins were analyzed with Western blot and detected by anti-Tau antibody (first panel). Inputs of SRPK2 (second panel), SRPK1 (third panel), and tau (fourth panel) were also shown. C, Tau binds to SRPK1 and SRPK2. GST or GST-Tau was transfected into 293 cells. The cell lysates were subjected to GST pull-down and detected with anti-SRPK1 or anti-SRPK2 antibody. Expressions of GST proteins (middle) and SRPKs (bottom) were also shown. D, Schematic diagram of various tau truncation mutants used in the in vitro binding assay. $\boldsymbol{E}$, SRPK2 interacts with the proline rich region of tau protein. Recombinant GST-Tau fragments purified from bacteria were incubated with cell lysates from HEK293 cells. The GST proteins were then pull downed using glutathione beads and the coprecipitated SRPK2 proteins were detected using anti-SRPK2 antibody (top). The expression of various tau fragments was also analyzed (bottom). $\boldsymbol{F}$, Schematic diagram of various SRPK2 truncation mutants used in the in vitro binding assay. G, SRPK2 interacts with tau through the region before the second kinase domain. Various GST-tagged SRPK truncation mutants were transfected into HEK293 cells. After $24 \mathrm{~h}$, the cells were infected with adenovirus overexpressing tau for $24 \mathrm{~h}$. GST pull-down assay was then performed and the precipitated proteins were analyzed by Western-blot with anti-Tau antibody (top). The expression of tau (middle) and SRPK2 fragments (bottom) were also examined. 

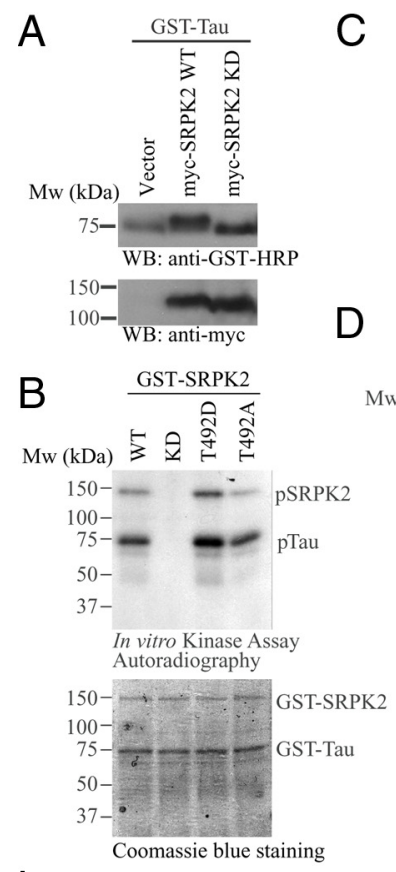

I
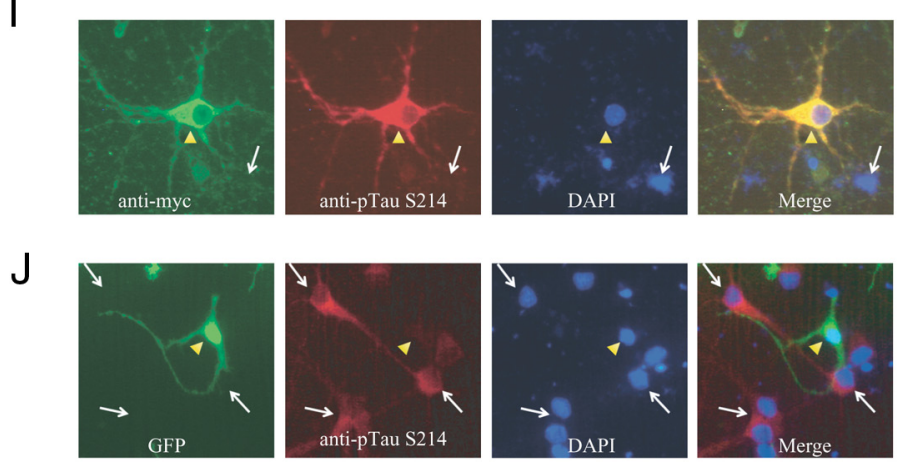

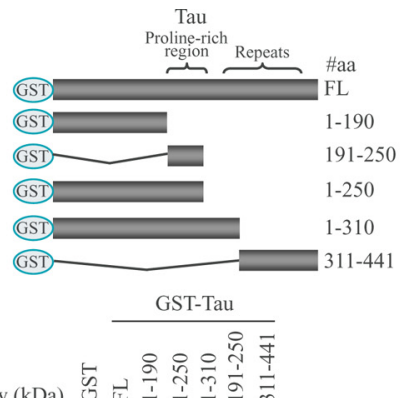

$E$

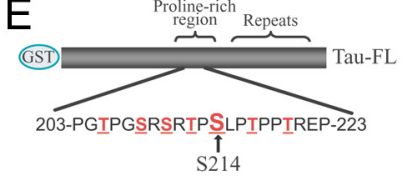

F
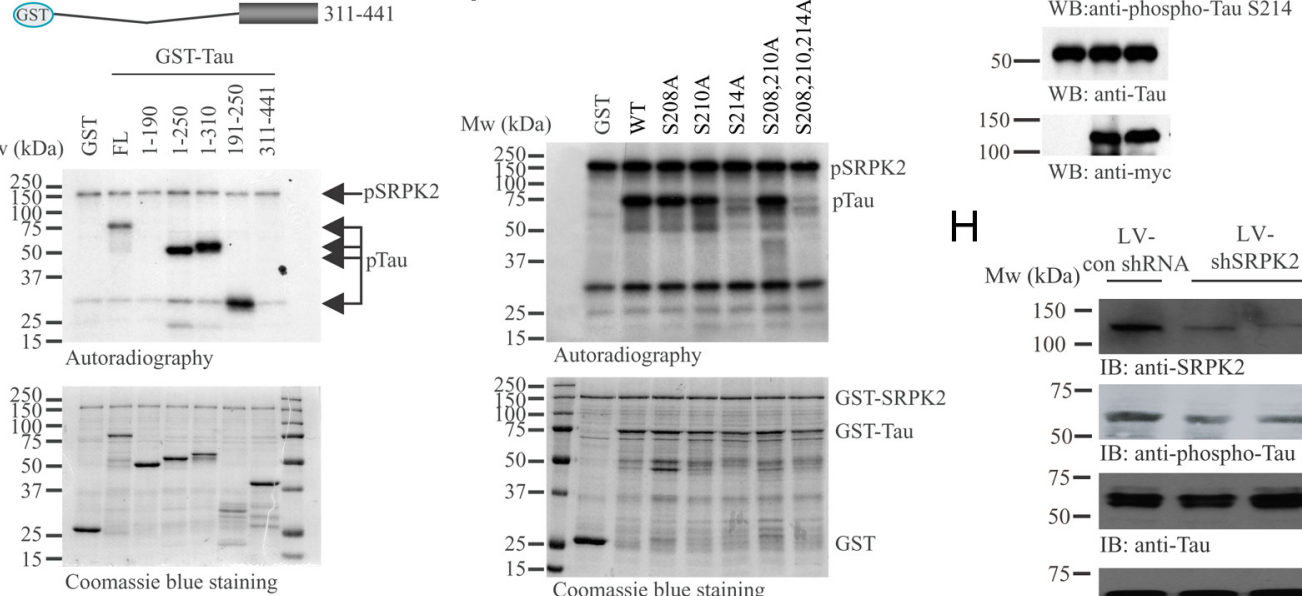
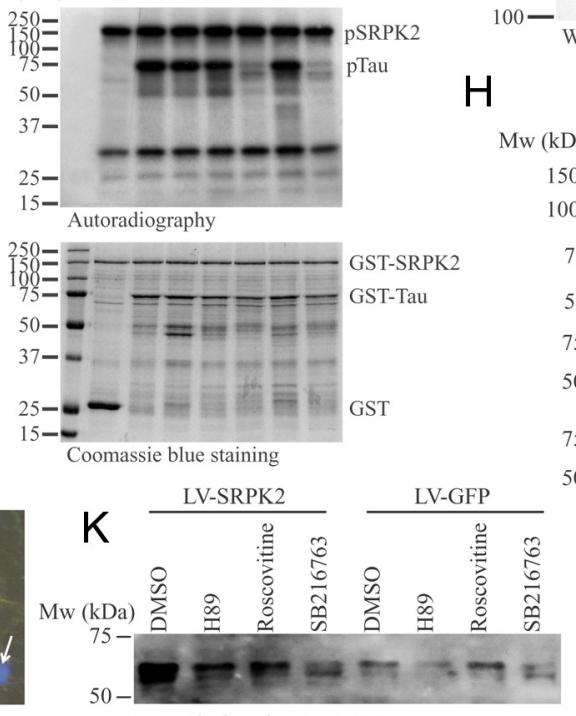

IB: anti-phospho-Tau S214

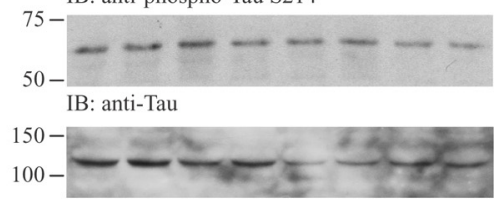

IB: anti-SRPK2

Figure 4. Tau is the physiological substrate of SRPK2. A, Wild-type SRPK2 affects the phosphorylation of tau in HEK293 cells. GST-Tau was co-transfected with empty vector, myc-SRPK2 WT, or myc-SRPK2-KD into HEK293 cells. Forty-eight hours after transfection, cell lysates were collected and analyzed by Western blot with anti-GST-HRP or anti-myc antibody. Migration of tau was slower in myc-SRPK2 WT overexpressed sample (top). Expression of the SRPK mutants were also verified (bottom). B, SRPK2 phosphorylates tau in vitro. Bacterial expressed and purified GST-Tau was incubated with GST-SRPK2 WT, GST-SRPK2 KD, GST-SRPK2 T492D, or GST-SRPK2 T492A in the presence of [ $\gamma^{32}$ P]-ATP. The reaction products were separated in SDS-PAGE and analyzed by autoradiography (top). The protein inputs were shown using Coomassie Blue staining (bottom). C, D, SRPK2 phosphorylates tau on the proline-rich region. Various tau truncates (C) were bacterially expressed, purified, and incubated with recombinant GST-SRPK2 in the presence of $\left[\gamma^{32} \mathrm{P}\right]-$-ATP. The reaction products were separated in SDS-PAGE and revealed by autoradiography (D). SRPK2 dramatically phosphorylates the tau truncates containing the proline-rich region. The protein inputs were also shown. $\boldsymbol{E}$, Schematic diagrams of the potential SRPK2 phosphorylation sites in tau. $\boldsymbol{F}$, SRPK2 phosphorylates tau on S214 residue. Various GST-tagged tau point mutants were bacterially expressed, purified, and then incubated with recombinant GST-SRPK2 in the presence of $\left[\gamma^{32}\right.$ P]-ATP. The reaction products were separated in SDS-PAGE and the phosphorylation was visualized by autoradiography (top). The proteins input were analyzed by Coomassie Blue staining (bottom). G, Overexpression of SRPK2 upregulates tau phosphorylation on S214. Primary neurons were infected with LV-GFP, LV-myc-SRPK2 WT, or LV-myc-SRPK2 KD for $72 \mathrm{~h}$. Tau phosphorylation was monitored using anti-phospho-Tau S214 antibody (top). Expressions of Tau (middle), SRPK2 WT, and SRPK2 KD were verified by anti-myc antibody (bottom). $\boldsymbol{H}$, Depletion of SRPK2 reduces tau phosphorylation on S214. Primary neurons were infected with lentivirus-expressing control shRNA (LV-con shRNA) or shSRPK2 for $48 \mathrm{~h}$. The cell lysates were resolved by SDS-PAGE, and the knockdown efficiency was examined using anti-SRPK2 antibody (first panel). Reduced expression of SRPK2 also inhibited tau phosphorylation on S214 (second panel). The expressions of total tau (third panel) and tubulin were also shown (fourth panel). I, Overexpression of SRPK2 in primary neuron induces tau phosphorylation on S214. Primary mouse neurons (P1) were infected with LV-myc-SRPK2 at DIV7 for $72 \mathrm{~h}$. After fixation in 4\% paraformaldehyde, the cells were costained with anti-myc and anti-phospho-Tau S214 antibodies. By comparing with the non-infected cells (white arrow), overexpression of SRPK2 (yellow triangle) significantly enhanced the phosphorylation of tau on S214. J, Depletion of SRPK2 inhibited tau phosphorylation on S214. Primary mouse neurons (P1) were infected with adenovirus expressing shSRPK2 at DIV7 for $72 \mathrm{~h}$. The cells were fixed and immunostained with anti-phospho-Tau S214 antibody. Phosphorylation of tau S214 was reduced in the virus-infected cells (yellow triangle) when compared with the non-infected cells (white arrow). $\boldsymbol{K}$, SRPK2-induced tau S214 phosphorylation is implicated with GSK3. Cortical neurons (DIV7) were infected with LV-GFP or LV-SRPK2 WT for 48 h, followed by $10 \mu \mathrm{m}$ H89 (PKA inhibitor), roscovitine (CDK5 inhibitor), or SB216763 (GSK3 inhibitor) stimulation for $6 \mathrm{~h}$. Phosphorylation of tau $\mathbf{} 214$ was then monitored by immunoblotting.

with the previous observation that apoptosis was enhanced in APP/PS1 mice (Li and Liu, 2010). However, the number of apoptotic cells was greatly diminished after SRPK2 depletion ( $0.13 \pm$ $0.03 \%$ of neurons in DG, $n=3$ ) (Fig. $5 C$, bottom right). In contrast, active caspase 3-positive cells were detected in neither LV-GFP nor LV-shSRPK2-injected WT mice (Fig. 5B, top), suggesting SRPK2 is responsible for neuronal apoptosis in pathological conditions only. We have also tested whether SRPK2 depletion in vivo alters the tau hyperphosphorylation in APP/PS1 brain. As shown in Figure 5C, the amount of PHF-tau was increased in APP/PS1 DG, which was reduced after LV-shSRPK2 infection. To further demonstrate that SRPK2 plays an active role in promoting tau aggregation through phosphorylation, we infected cultured neurons with LV-myc-SRPK2 WT or LV-mycSRPK2 KD. While wild-type SRPK2 significantly increased the amount of tau aggregates, neurons with SRPK2 KD overexpres- 
A
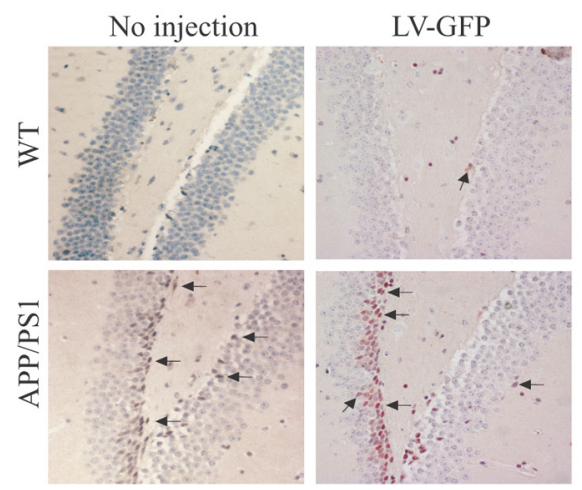

LV-shSRPK2
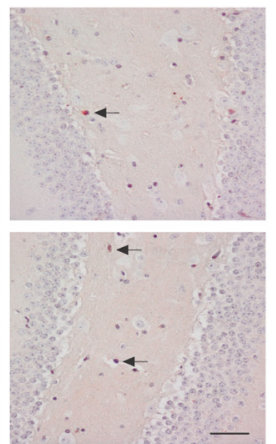

IHC: anti-pTau S214

C

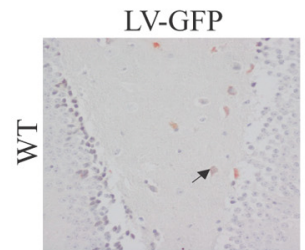

\section{LV-shSRPK2}
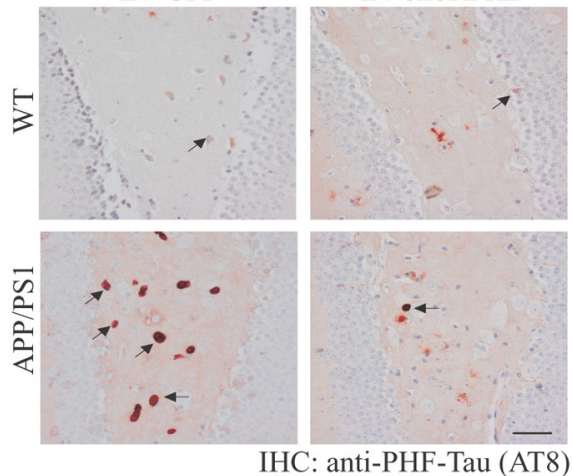

B

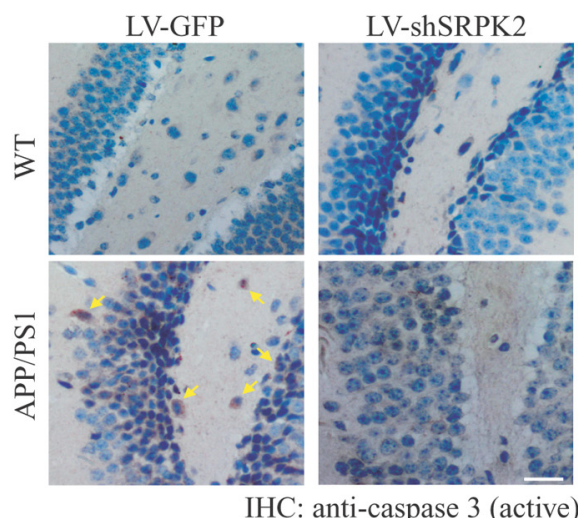

D
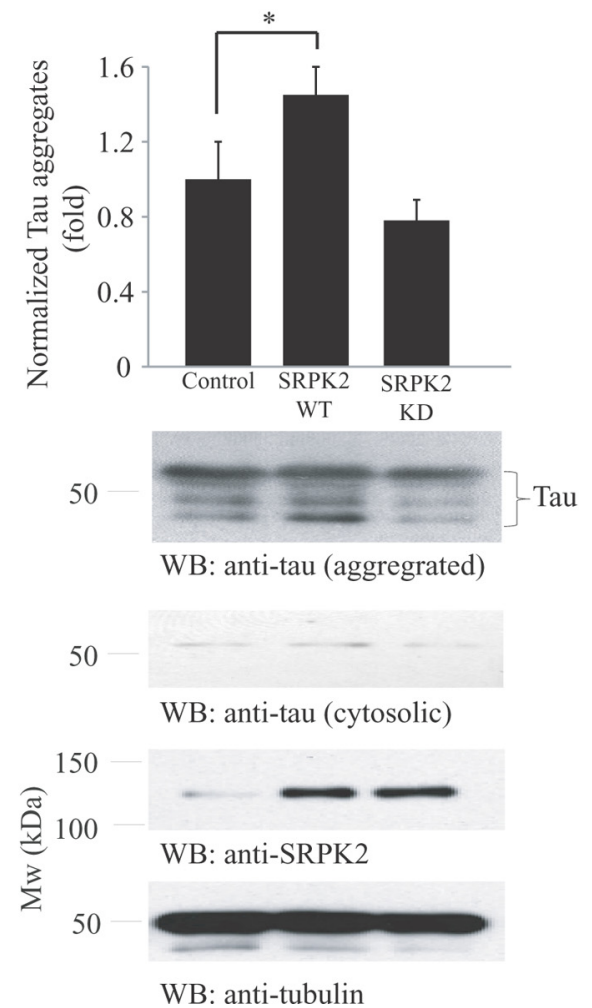

Figure 5. SRPK2 promotes tau hyperphosphorylation. $A$, Depletion of SRPK2 reduces tau S214 phosphorylation in APP/PS1 DG. Immunohistochemical staining of tau S214 phosphorylation was performed in LV-GFP or LV-shSRPK2 virus infected DG in WT or APP/PS1 mice. Examples of cells showing positive signal were indicated by arrows. Scale bar, $50 \mu \mathrm{m}$. $\boldsymbol{B}$, Depletion of SRPK2 reduces apoptosis in APP/PS1 DG. Immunohistochemical staining of active caspase 3 was performed in LV-GFP or LV-shSRPK2 virus infected DG of WT or APP/PS1 mice. Examples of cell showing positive signal were indicated by arrows. Scale bar, $25 \mu \mathrm{m}$. C, Depletion of SRPK2 reduces the amount of PHF-tau in APP/PS1 DG. Immunohistochemical staining of PHF-tau using AT8 antibody was performed in LV-GFP or LV-shSRPK2 virus infected DG of WT or APP/PS1 mice. Examples of cell showing positive signal were indicated by arrows. Scale bar, $50 \mu \mathrm{m}$. $\boldsymbol{D}, 0$ verexpression of SRPK2 promotes tau aggregation in primary neurons. Primary rat neurons (DIV10) were infected with LV-GFP, LV-myc-SRPK2, or LV-SRPK2-KD for 48 h. The amount of tau in different cellular fractions were separated by ultracentrifugation, detected by Western blot analysis, and densitometrically quantified (first panel, $p<0.05$, Student's $t$ test, $n=3$ ). Expressions of various SRPK2 mutants (fourth panel), cytosolic tau (second panel), aggregated tau (third panel), and tubulin (fifth panel) were also examined.

sion had no effect on the amount of cellular tau aggregates (Fig. $5 D)$. Thus, SRPK2 is important to promote tau phosphorylation both in vitro and in vivo.

\section{SRPK2 inhibits tau-dependent microtubule polymerization and neurite outgrowth}

To investigate whether SRPK2 modulates the function of tau in assisting microtubule polymerization, we carried out an in vitro microtubule polymerization assay using purified tubulins in the presence of various recombinant tau proteins. In this assays, tau was phosphorylated by SRPK2 before incubation with tubulin.
While non-phosphorylated tau strongly promoted microtubule assembly, SRPK2-phosphorylation on tau substantially inhibited the polymerization (Fig. $6 \mathrm{~A}$ ). We have also assessed the ability of various tau phosphorylation mutants in assisting tubulin polymerization. As expected, tau S214E mutant that mimics the phosphorylation of tau on S214 compromised the ability of tau to promote tubulin polymerization (Fig. $6 \mathrm{~B}$ ). Since tau is an important factor in promoting axon elongation (Shea et al., 1992), we wondered whether overexpressing SRPK2 alters the axon elongation in intact cells. We transfected primary neurons with GFP, GFP-SRPK2-WT, or GFP-SRPK2-KD at DIV7 for $24 \mathrm{~h}$. The neu- 
rons were then stained with the axon marker (anti-Tau-1 antibody) and the length of primary neurites was analyzed. We observed that overexpression of SRPK2 significantly reduced the axon length compared with that of GFP transfected cells (Fig. 6C). Consistently, overexpression of wild-type tau in primary neurons potently enhanced the axon length, which was partially decreased in tau S214E transfected cells (Fig. 6D). These data are in good agreement with the observation that SRPK2 phosphorylation reduced taumediated microtubule polymerization in vitro. In humans, intracellular accumulation of PHF-tau disrupts the cytoskeleton and contributes to axonal and dendritic degeneration. It has been reported that dendrite densities are reduced by $60 \%$ in AD hippocampus (Falke et al., 2003). If SRPK2 is a physiological kinase that promotes tau aggregation during AD progression, depletion of SRPK2 should alleviate the number of damaged dendrites in APP/PS1 mice. Similar to the report in human study (Falke et al., 2003), the dendrite density was greatly reduced in APP/PS1 DG as revealed by MAP2 staining (Fig. 6E, bottom left). Significantly, the number of dendrite was increased after SRPK2 depletion in APP/PS1 mice (Fig. 6E, bottom right), strongly suggesting that activation of SRPK2 in AD crumbles the neuronal morphology. Hence, SRPK2 phosphorylation of tau regulates its role in assisting microtubule polymerization and neurite elongation.

\section{Discussion}

SRPKs recognize SR repeats and phosphorylate serine in the SR proteins (Koizumi et al., 1999; Daub et al., 2002; Mathew et al., 2008). In addition to acting as a modifier of cell cycle progression and apoptotic pathways (Jang et al., 2008; Jang et al., 2009; Hong et al., 2011), our findings demonstrate that SRPK2 is a negative regulator of neuronal functions in $\mathrm{AD}$, possibly through modulating the phosphorylation of tau. Surprisingly, SRPK2 phosphorylates tau S214 following the proline residue but not the adjacent SRSR consensus repeat, indicating that SRPK2 may also phosphorylate unconventional sites like the "PSLP" in tau (Fig. 4E). In addition, SRPK2 binds to tau protein through the spacer region (aa 384-438) preceding the second kinase domain (Fig. $3 F$ ), which fits with our previous observation that this region is responsible for cytoplasmic localization of SRPK2 (Hong et al., 2011). Removal of the unique spacer between the two kinase domains in SRPK has little effect on the kinase activity but
A

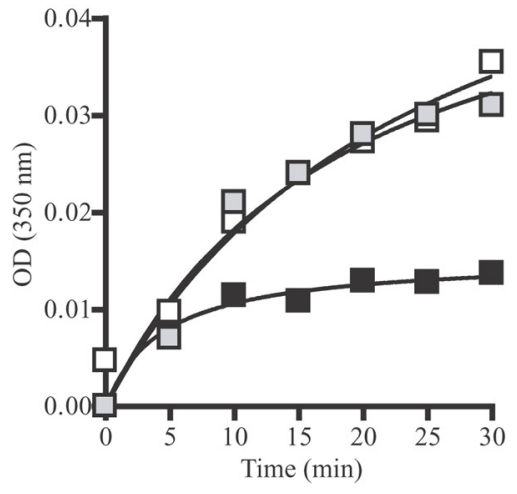

B
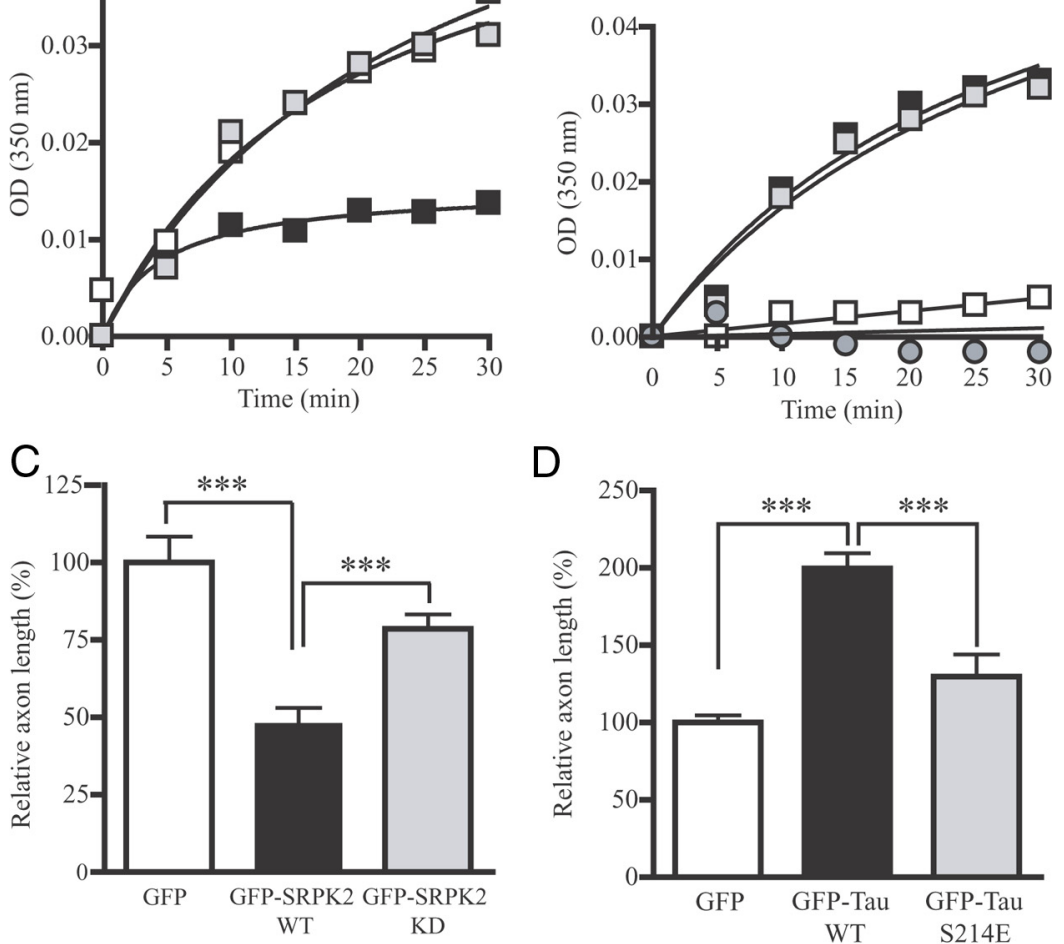

D

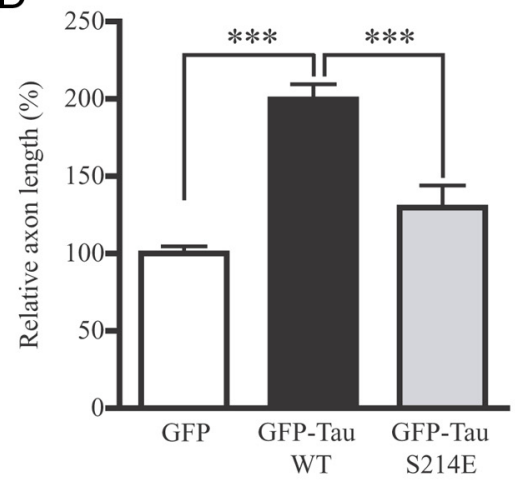

E

LV-GFP
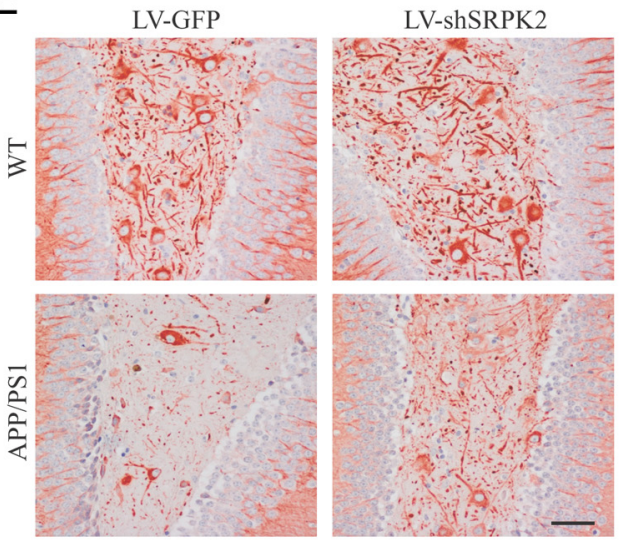

IHC: anti-MAP2

Figure 6. SRPK2 inhibits tau-dependent microtubule polymerization and neurites outgrowth. A, SRPK2 phosphorylation inhibits tau-promoted microtubule polymerization. Recombinant GST-Tau or GST-Tau S214A was first incubated with purified GST or GST-SRPK2 to promote tau phosphorylation. The reaction products were then incubated with purified bovine brain tubulin. The formation of microtubule was monitored by measuring the absorbance in a spectrophotometer at $350 \mathrm{~nm}$ (open square: Tau WT + GST; solid square: Tau WT + SRPK2; gray square: Tau S214A + SRPK2). B, Tau S214E mutant fails to promote microtubule polymerization in vitro. GST, GST-Tau, GST-Tau S214A, or GST-Tau S214E recombinant protein was incubated with purified bovine brain tubulin. The turbidity of polymerized microtubule was measured at $350 \mathrm{~nm}$ (open square: GST; solid square: GST-tau; gray square: GST-Tau S214A; gray circle: GST-tau S214E). C, SRPK2 represses axon elongation in primary neurons. Primary neurons (DIV 7) were transfected with GFP, GFP-SRPK2 WT, or GFP-SRPK2 KD for $24 \mathrm{~h}$. The cells were then fixed and immunostained using anti-Tau- 1 antibody to display the axons. The lengths of the primary neurites were measured. Expression of SRPK2 significantly inhibited the axonal growth of primary neuron ( ${ }^{* * *} p<0.001$, Student's $t$ test, $n=20$ ). Scale bar, $200 \mu \mathrm{m}$. D, The ability of tau to promote axon elongation in primary neuron was decreased by S214E mutation. Primary neurons (DIV 7) were transfected with GFP, GFP-Tau, or GFP-Tau S214E for $24 \mathrm{~h}$. The cells were then fixed and the images of the transfected neurons were captured under fluorescent microscope. Overexpression of wild-type tau significantly enhanced the axonal elongation ${ }^{* * *} p<0.001$, Student's $t$ test, $n=20$ ). Scale bar, $200 \mu \mathrm{m}$. $\boldsymbol{E}$, Increased neurite density in SRPK2-depleted APP/PS1 mice. The dendrites of cells in various virus-infected DG were stained using anti-MAP2 antibody. Scale bars: $50 \mu \mathrm{m}$. 
triggers its nuclear translocation to induce aggregation of splicing factors in the nucleus (Ding et al., 2006). Interestingly, this region is an intrinsically disordered motif that shares little homology between SRPK2 and SRPK1 (Wang et al., 1998; Plocinik et al., 2011). Thus, it remains unclear why tau associates with both SRPKs on a region that is structurally different between the two isoforms (Fig. 3B). A possible explanation is that the structural conformations of the SRPK regions for tau association are similar although the primary amino acid sequences are not well conserved.

While most neurons are terminally differentiated that remain in non-dividing $G_{0}$ phase, aberrant cell cycle reactivation provokes neuronal cell death (Yang and Herrup, 2007; Lee et al., 2009b). In AD neurons, cell cycle regulators like cyclin D, Cdk4, and PCNA are significant elevated, indicating that dysregulation of these components is a contributor to the death of specific neurons in AD (Busser et al., 1998; Lee et al., 2009a). Interestingly, tau phosphorylation is also a cell cycle-regulated event that tau S214 is prominently phosphorylated during metaphase (Illenberger et al., 1998). Phosphorylation of this residue strongly decreases the tau-microtubule interaction in vitro and suppresses microtubule assembly (Fig. 6), suggesting the phosphorylation is a key event in the detachment of tau from microtubules during mitosis. Since SRPK2 mediates postmitotic neurons to reenter the cell cycle by triggering cyclin D1, Cdk4, and cyclin B1 expressions (Jang et al., 2009), and since depletion of SRPK2 in APP/PS1 brain suppresses neuronal apoptosis (Fig. 5B), our finding that SRPK2 is activated in AD neurons thus identifies a key molecule in linking the cell cycle, tau hyperphosphorylation, and neuronal death.

Tau phosphorylation can be recognized by antibodies against multiple epitopes such as the famous AT100, PHF, and AT8 (Hampel et al., 2010). Formations of these pathological tau epitopes need serial phosphorylations of tau at different sites. For instance, the generation of AT100 epitope needs the sequential phosphorylation of tau at S214, then T212 and T217 (Yoshida and Goedert, 2006). We have identified that SRPK2 is a novel tau kinase that phosphorylates tau at S214, suggesting it may initiate the hyperphosphorylation of tau and work in concert with other tau kinases to form pathological tau epitope in vivo. Indeed, we found that the PHF-tau in the APP/PS1 DG was reduced after SRPK2 depletion, which further supports the notion that SRPK2 plays a critical role for tau aggregation. It is interesting to note that phosphorylation of tau on S262 and S214 not only detaches it from microtubules but also protects it from aggregation into PHF in vitro (Schneider et al., 1999), which is in contrast to the general belief that abnormal phosphorylation of tau should promote its aggregation in PHF. However, contrary observations have also been reported. For example, Necula and Kurset ( 2004) observed that pseudophosphorylation mutant of tau (S214E) increased tau fibrillization in vitro. Similarly, Pei et al. (2006) proposed that phosphorylation of tau on S214 neutralizes the protective effect of S262 phosphorylation and thus causes the self-assembly of tau into filaments. Therefore, the specific role of tau S214 on PHF formation is still unclear but our observation of phosphorylation of tau by SRPK2 favors the formation of PHF in mice. It is noteworthy that tau S214 could be phosphorylated by multiple kinases including PKA and GSK (Scott et al., 1993; Liu et al., 2002). Inhibition of these kinases in neurons resulted in reduced tau S214 phosphorylation (Fig. $4 K$ ). When SRPK2 is overexpressed, tau phosphorylation is robustly increased. Inhibition of PKA and CDK5 somehow reduced tau S214 phosphorylation by SRPK2. Remarkably, SRPK2 overexpression failed to increase tau S214 phosphorylation when GSK3 activity was suppressed, suggesting GSK3 could also modulate the SRPK2-induced tau S214 phosphorylation in addition to acting as a tau kinase per se. Surprisingly, inhibition of CDK5 in control virus-infected neurons by roscovitine did not reduce tau S214 phosphorylation, although CDK5 can phosphorylate tau on S214 in vitro (Liu et al., 2002). Presumably, the tau phosphorylation is counter-balanced by the activation of extracellular signal-regulated kinase (ERK, another tau S214 kinase), which is the consequence of CDK5 inhibition (Zheng et al., 2007; Kim et al., 2011).

Tauopathy is a group of disorders characterized by the accumulation of hyperphosphorylated tau protein in the brain, resulting in dementia (Shiryaev et al., 2010). Therefore, abnormal tau accumulation in APP/PS1 mice causes a poor performance in memory tasks like the Morris water maze as shown in the current study. Interestingly, SRPK2 depletion alleviates the behavioral deterioration in APP/PS1 mice (Fig. 2C). The results suggest that activation of SRPK2 may promote the behavior deterioration in APP/PS1 mice. Our electrophysiology studies also show that the LTP is significantly impaired in APP/PS1 mice, whereas SRPK2 silencing rescues the defective synaptic plasticity (Fig. 2D). In addition, averaged PPF amplitude in LV-GFP injected APP/PS1 mice is lower than the WT animals under the same virus treatment, but is significantly increased in LV-shSRPK2 infected APP/ PS1 mice, indicating that SRPK2 depletion rescues the presynaptic neuronal functions and improves synaptic plasticity in APP/PS1 mice (Fig. 2E). Since tau is an important protein in maintaining the morphological integrity and synapse density of neurons (Perez-Cruz et al., 2011), presumably, the impaired synaptic function in APP/PS1 mice is a result of reduced dendritic arborization, which could be rescued by SRPK2 inactivation (Fig. $6 E$ ). Together, our results support that tau is an important target of SRPK2 in neurons and modulation of the SRPK2/Tau signaling pathway may represent a promising strategy to prevent neuronal cell death or malfunction during the progression of $\mathrm{AD}$.

\section{References}

Billingsley ML, Kincaid RL (1997) Regulated phosphorylation and dephosphorylation of tau protein: effects on microtubule interaction, intracellular trafficking and neurodegeneration. Biochem J 323:577-591. Medline

Busser J, Geldmacher DS, Herrup K (1998) Ectopic cell cycle proteins predict the sites of neuronal cell death in Alzheimer's disease brain. J Neurosci 18:2801-2807. Medline

Chi Y, Hong Y, Zong H, Wang Y, Zou W, Yang J, Kong X, Yun X, Gu J (2009) CDK11p58 represses vitamin D receptor-mediated transcriptional activation through promoting its ubiquitin-proteasome degradation. Biochem Biophys Res Commun 386:493-498. CrossRef Medline

Daub H, Blencke S, Habenberger P, Kurtenbach A, Dennenmoser J, Wissing J, Ullrich A, Cotten M (2002) Identification of SRPK1 and SRPK2 as the major cellular protein kinases phosphorylating hepatitis B virus core protein. J Virol 76:8124-8137. CrossRef Medline

Ding JH, Zhong XY, Hagopian JC, Cruz MM, Ghosh G, Feramisco J, Adams JA, Fu XD (2006) Regulated cellular partitioning of SR protein-specific kinases in mammalian cells. Mol Biol Cell 17:876-885. Medline

Dolan PJ, Johnson GV (2010) The role of tau kinases in Alzheimer's disease. Curr Opin Drug Discov Devel 13:595-603. Medline

Falke E, Nissanov J, Mitchell TW, Bennett DA, Trojanowski JQ, Arnold SE (2003) Subicular dendritic arborization in Alzheimer's disease correlates with neurofibrillary tangle density. Am J Pathol 163:1615-1621. CrossRef Medline

Giannakouros T, Nikolakaki E, Mylonis I, Georgatsou E (2011) Serinearginine protein kinases: a small protein kinase family with a large cellular presence. FEBS J 278:570-586. CrossRef Medline

Götz J, Ittner LM, Kins S (2006) Do axonal defects in tau and amyloid precursor protein transgenic animals model axonopathy in Alzheimer's disease? J Neurochem 98:993-1006. CrossRef Medline

Hampel H, Blennow K, Shaw LM, Hoessler YC, Zetterberg H, Trojanowski JQ 
(2010) Total and phosphorylated tau protein as biological markers of Alzheimer's disease. Exp Gerontol 45:30-40. CrossRef Medline

Hong Y, Jang SW, Ye K (2011) The N-terminal fragment from caspasecleaved serine/arginine protein-specific kinase2 (SRPK2) translocates into the nucleus and promotes apoptosis. J Biol Chem 286:777-786. CrossRef Medline

Hoover BR, Reed MN, Su J, Penrod RD, Kotilinek LA, Grant MK, Pitstick R, Carlson GA, Lanier LM, Yuan LL, Ashe KH, Liao D (2010) Tau mislocalization to dendritic spines mediates synaptic dysfunction independently of neurodegeneration. Neuron 68:1067-1081. CrossRef Medline

Illenberger S, Zheng-Fischhöfer Q, Preuss U, Stamer K, Baumann K, Trinczek B, Biernat J, Godemann R, Mandelkow EM, Mandelkow E (1998) The endogenous and cell cycle-dependent phosphorylation of tau protein in living cells: implications for Alzheimer's disease. Mol Biol Cell 9:14951512. Medline

Ittner LM, Götz J (2011) Amyloid-beta and tau-a toxic pas de deux in Alzheimer's disease. Nat Rev Neurosci 12:65-72. CrossRef Medline

Jang SW, Yang SJ, Ehlén A, Dong S, Khoury H, Chen J, Persson JL, Ye K (2008) Serine/arginine protein-specific kinase 2 promotes leukemia cell proliferation by phosphorylating acinus and regulating cyclin A1. Cancer Res 68:4559-4570. CrossRef Medline

Jang SW, Liu X, Fu H, Rees H, Yepes M, Levey A, Ye K (2009) Interaction of Akt-phosphorylated SRPK2 with 14-3-3 mediates cell cycle and cell death in neurons. J Biol Chem 284:24512-24525. CrossRef Medline

Kim I, Park EJ, Seo J, Ko SJ, Lee J, Kim CH (2011) Zinc stimulates tau S214 phosphorylation by the activation of Raf/mitogen-activated protein kinase-kinase/extracellular signal-regulated kinase pathway. Neuroreport 22:839-844. Medline

Koizumi J, Okamoto Y, Onogi H, Mayeda A, Krainer AR, Hagiwara M (1999) The subcellular localization of SF2/ASF is regulated by direct interaction with SR protein kinases (SRPKs). J Biol Chem 274: 11125-11131. CrossRef Medline

Lee HG, Casadesus G, Zhu X, Castellani RJ, McShea A, Perry G, Petersen RB, Bajic V, Smith MA (2009a) Cell cycle re-entry mediated neurodegeneration and its treatment role in the pathogenesis of Alzheimer's disease. Neurochem Int 54:84-88. CrossRef Medline

Lee HG, Casadesus G, Nunomura A, Zhu X, Castellani RJ, Richardson SL, Perry G, Felsher DW, Petersen RB, Smith MA (2009b) The neuronal expression of MYC causes a neurodegenerative phenotype in a novel transgenic mouse. Am J Pathol 174:891-897. CrossRef Medline

Lee SE, Simons SB, Heldt SA, Zhao M, Schroeder JP, Vellano CP, Cowan DP, Ramineni S, Yates CK, Feng Y, Smith Y, Sweatt JD, Weinshenker D, Ressler KJ, Dudek SM, Hepler JR (2010) RGS14 is a natural suppressor of both synaptic plasticity in CA2 neurons and hippocampal-based learning and memory. Proc Natl Acad Sci U S A 107:16994-16998. CrossRef Medline

Li N, Liu GT (2010) The novel squamosamide derivative FLZ enhances $\mathrm{BDNF} / \mathrm{TrkB} / \mathrm{CREB}$ signaling and inhibits neuronal apoptosis in APP/PS1 mice. Acta Pharmacol Sin 31:265-272. CrossRef Medline

Liu F, Iqbal K, Grundke-Iqbal I, Gong CX (2002) Involvement of aberrant glycosylation in phosphorylation of tau by cdk5 and GSK-3beta. FEBS Lett 530:209-214. CrossRef Medline

Lorenzo A, Yankner BA (1994) Beta-amyloid neurotoxicity requires fibril formation and is inhibited by congo red. Proc Natl Acad Sci U S A 91: 12243-12247. CrossRef Medline

Martin L, Latypova X, Terro F (2011) Post-translational modifications of tau protein: implications for Alzheimer's disease. Neurochem Int 58:458 471. CrossRef Medline

Mathew R, Hartmuth K, Möhlmann S, Urlaub H, Ficner R, Lührmann R (2008) Phosphorylation of human PRP28 by SRPK2 is required for integration of the U4/U6-U5 tri-snRNP into the spliceosome. Nat Struct Mol Biol 15:435-443. CrossRef Medline

Necula M, Kuret J (2004) Pseudophosphorylation and glycation of tau protein enhance but do not trigger fibrillization in vitro. J Biol Chem 279: 49694-49703. CrossRef Medline

Oddo S, Caccamo A, Shepherd JD, Murphy MP, Golde TE, Kayed R, Mether- ate R, Mattson MP, Akbari Y, LaFerla FM (2003) Triple-transgenic model of Alzheimer's disease with plaques and tangles: intracellular Abeta and synaptic dysfunction. Neuron 39:409-421. CrossRef Medline

Pei JJ, An WL, Zhou XW, Nishimura T, Norberg J, Benedikz E, Götz J, Winblad B (2006) P70 S6 kinase mediates tau phosphorylation and synthesis. FEBS Lett 580:107-114. CrossRef Medline

Perez-Cruz C, Nolte MW, van Gaalen MM, Rustay NR, Termont A, Tanghe A, Kirchhoff F, Ebert U (2011) Reduced spine density in specific regions of CA1 pyramidal neurons in two transgenic mouse models of Alzheimer's disease. J Neurosci 31:3926-3934. CrossRef Medline

Plocinik RM, Li S, Liu T, Hailey KL, Whitesides J, Ma CT, Fu XD, Gosh G, Woods VL Jr, Jennings PA, Adams JA (2011) Regulating SR protein phosphorylation through regions outside the kinase domain of SRPK1. J Mol Biol 410:131-145. CrossRef Medline

Schneider A, Biernat J, von Bergen M, Mandelkow E, Mandelkow EM (1999) Phosphorylation that detaches tau protein from microtubules (Ser262, Ser214) also protects it against aggregation into Alzheimer paired helical filaments. Biochemistry 38:3549-3558. CrossRef Medline

Scott CW, Spreen RC, Herman JL, Chow FP, Davison MD, Young J, Caputo CB (1993) Phosphorylation of recombinant tau by cAMP-dependent protein kinase. Identification of phosphorylation sites and effect on microtubule assembly. J Biol Chem 268:1166-1173. Medline

Shea TB, Beermann ML, Nixon RA, Fischer I (1992) Microtubuleassociated protein tau is required for axonal neurite elaboration by neuroblastoma cells. J Neurosci Res 32:363-374. CrossRef Medline

Shiryaev N, Jouroukhin Y, Gozes I (2010) 3R tau expression modifies behavior in transgenic mice. J Neurosci Res 88:2727-2735. Medline

Sperling RA, Dickerson BC, Pihlajamaki M, Vannini P, LaViolette PS, Vitolo OV, Hedden T, Becker JA, Rentz DM, Selkoe DJ, Johnson KA (2010) Functional alterations in memory networks in early Alzheimer's disease. Neuromolecular Med 12:27-43. CrossRef Medline

Spillantini MG, Crowther RA, Goedert M (1996) Comparison of the neurofibrillary pathology in Alzheimer's disease and familial presenile dementia with tangles. Acta Neuropathol 92:42-48. CrossRef Medline

Szulwach KE, Li X, Smrt RD, Li Y, Luo Y, Lin L, Santistevan NJ, Li W, Zhao X, Jin P (2010) Cross talk between microRNA and epigenetic regulation in adult neurogenesis. J Cell Biol 189:127-141. CrossRef Medline

Trinchese F, Liu S, Battaglia F, Walter S, Mathews PM, Arancio O (2004) Progressive age-related development of Alzheimer-like pathology in APP/ PS1 mice. Ann Neurol 55:801-814. CrossRef Medline

Wang HY, Lin W, Dyck JA, Yeakley JM, Songyang Z, Cantley LC, Fu XD (1998) SRPK2: a differentially expressed SR protein-specific kinase involved in mediating the interaction and localization of pre-mRNA splicing factors in mammalian cells. J Cell Biol 140:737-750. CrossRef Medline

Wang HY, Arden KC, Bermingham JR Jr, Viars CS, Lin W, Boyer AD, Fu XD (1999) Localization of serine kinases, SRPK1 (SFRSK1) and SRPK2 (SFRSK2), specific for the SR family of splicing factors in mouse and human chromosomes. Genomics 57:310-315. CrossRef Medline

Yang Y, Herrup K (2007) Cell division in the CNS: protective response or lethal event in post-mitotic neurons? Biochim Biophys Acta 1772: 457-466. CrossRef Medline

Yoshida H, Goedert M (2006) Sequential phosphorylation of tau protein by cAMP-dependent protein kinase and SAPK4/p38delta or JNK2 in the presence of heparin generates the AT100 epitope. J Neurochem 99:154164. CrossRef Medline

Yoshiyama Y, Higuchi M, Zhang B, Huang SM, Iwata N, Saido TC, Maeda J, Suhara T, Trojanowski JQ, Lee VM (2007) Synapse loss and microglial activation precede tangles in a P301S tauopathy mouse model. Neuron 53:337-351. CrossRef Medline

Zhang X, Li F, Bulloj A, Zhang YW, Tong G, Zhang Z, Liao FF, Xu H (2006) Tumor-suppressor PTEN affects tau phosphorylation, aggregation, and binding to microtubules. FASEB J 20:1272-1274. CrossRef Medline

Zheng YL, Li BS, Kanungo J, Kesavapany S, Amin N, Grant P, Pant HC (2007) Cdk5 Modulation of mitogen-activated protein kinase signaling regulates neuronal survival. Mol Biol Cell 18:404-413. Medline 